Revista do CESP, Belo Horizonte, v.35, n.54, p. 11-20, 2015

\title{
Os cadernos de campo de um etnopoeta: errância e registro nos poemas sobre Timor ${ }^{1}$
}

\section{The fieldwork notebooks of an etnopoet. Wandering and the need to register in the Timor poems}

\author{
Duarte Drumond Braga \\ Universidade de São Paulo - FAPESP \\ duartedbraga@gmail.com
}

Resumo: O presente ensaio pretende dar conta da forma como a poesia de Ruy Cinatti é um lugar de negociação da alteridade. Daqui deriva que, nos poemas sobre Timor, a poesia cinattiana se recusa a assumir as poéticas do exotismo, do orientalismo e do primitivo. Em seguida, analisam-se algumas das relações entre poesia e ciência para a construção destes poemas.

Palavras-chave: Cinatti; Timor; alteridade; registro.

Abstract: This essay intends to explain how the poetry of Ruy Cinatti can be taken, especially in the Timor poems, as a place of negotiation of otherness. Deriving from this, his work refuses to take on the poetics of Exoticism, Orientalism and the primitive. The paper also analyses some of the relations between Poetry and Science regarding the writing of the Timor poems.

Keywords: Cinatti; Timor; otherness; record

Recebido em 13 de novembro de 2015

Aprovado em 15 de dezembro de 2015

\footnotetext{
${ }^{1}$ Texto oriundo de pesquisa da Fundação de Amparo à Pesquisa do Estado de São Paulo (número do processo 2014/00829-8)
} 


\section{As ambivalências do "discurso limite"}

Na poesia portuguesa contemporânea, poucos são os autores que se dedicaram à representação dos mundos a leste da Europa. Como lembrou Jorge de Sena no prefácio a Paisagens timorenses com vultos, os literatos "em matéria de insulíndias não vão além das livrarias do Boulevard Saint Michel". 2 Quando sucedeu irem mais além, essa representação muitas vezes se deu a conhecer por via das poéticas do "primitivo" ou do "exótico". Ruy Cinatti é, segundo creio, uma grande exceção a este quadro, ou melhor, é um poeta que o trabalha em sentido desconstrutivo. É este o cerne da questão e também o nó de difícil deslinde: sem deixar de ser um autor que parte da tradição colonial portuguesa, Cinatti dela consegue deslocar-se através da crítica daqueles três discursos acima referidos. Com efeito, o poeta relativiza e mesmo questiona as poéticas do "exótico", do "selvagem" ou do "primitivo".

O presente ensaio pretende dar conta da centralidade da inscrição antropológica na poesia cinattiana, isto é, entender o seu interesse em registar o outro, sobretudo na medida em que esta poesia é um lugar de negociação da alteridade. O que posso chamar "inscrição antropológica" seria, nesta perspectiva, central para entender o seu funcionamento interno. Em seguida se verá como isso mobiliza e traz consequências para a relação entre poesia e ciência.

O lugar em que esta questão melhor se revela são os poemas sobre Timor, como seria de esperar. Com efeito, no encalço do poeta de herança decadentista e de prática parnasiana Alberto Osório de Castro, que viveu nessa colônia portuguesa, não exagerarei ao afirmar que Cinatti é um dos primeiros poetas a criar um discurso literário estruturado sobre o local. Trata-se de dar rosto a um território colonial tradicionalmente pouco atendido por Portugal e de construir um corpus de escrita plural sobre o território (expresso também em abundantes escritos científicos) no seio do qual estes poemas devem ser lidos.

Os versos de Uma sequência timorense, de 1970, ecoam a permanência de Cinatti em um território isolado e empobrecido, como no conhecido poema intitulado "Propósito inadiável":

${ }^{2}$ SENA. Prefácio a Paisagens timorenses com vultos, p. 485. 
O que magoa é ver o pobre timorense esquálido beber

água do pântano, onde se escoam lixos, comer poeira e saudar-me, quando rodo na estrada, deus ocioso.

Tantos e tantos outros, timorenses esquálidos, olham-me como se dever fosse abrir covas, plantar repasto de milho, arroz e carne, encher copos vazios, de bebedeira e sonho, que não magoe, mortifique o ócio, reanime o tempo.

Fugir é melhor que prometer esperança em melhores dias.

Fugir é atrasar o discurso limite travado pelas rodas da dúvida maníaca.

Eu não prometo nada. Invoco os montes feridos pela luz, o mar que me circunda em Díli terra-tédio e de má gente.

Afino-me pelo timbre limpo das almas dos timorenses esquálidos que me soletram vivo.

E sigo, limpo na alma e no rosto, sujeito à condição que me redime. Os Timorenses só terão razão quando me matarem. ${ }^{3}$

${ }^{3}$ CINATTI. Obra poética, p. 41-42. 
Proponho, nas linhas seguintes, uma leitura deste poema como um violento deslocamento do lugar epistemológico do colonizador. Logo de início devemos ter presente que Cinatti fez parte da burocracia colonial portuguesa e que esta cena foi experienciada numa das suas muitas viagens pelo interior da ilha. Tais viagens de reconhecimento não originaram narrativas de viagem, com a clássica preocupação em relatar o "outro", penetrando e desvendando sua cultura, mas algo de diverso. O poema começa por promover uma encenação irónica do colonizador enquanto descobridor: "quando/ rodo na estrada,/deus ocioso". ${ }^{4} \mathrm{O}$ eu lírico apresenta-se como deus ocioso que visita o timorense, numa ironia que desconstrói o lugar de autoridade do estrangeiro. Em outro momento do texto, o poeta coloca-se no lugar do colonizado, que se vê forçado a obedecer a uma ordem absurda:

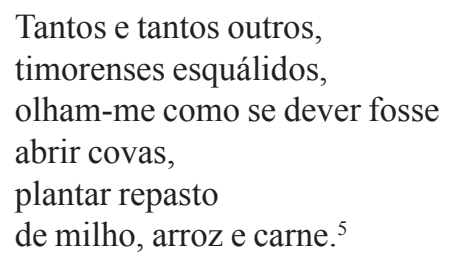

O objeto-timorense não é um objeto, nem é um sujeito que fala porque o sujeito colonial permite que ele fale, mas alguém que desde o início ocupa o lugar central do poema. Com efeito, o poema encerra com a inversão total desta situação:
Afino-me pelo timbre
limpo das almas
dos timorenses esquálidos
que me soletram vivo. ${ }^{6}$

O eu lírico passa a ser representado, de uma forma dolorosa, na qual o ato de ser soletrado, isto é, de ser dito ou representado vivo equivale à encenação textual de uma postura talvez vingativa por parte do "objeto". Ora, isto tem seu auge num sacrifício final do sujeito, que implica um apagamento no seio do discurso, em que o processo de "abdicação" (para

\footnotetext{
${ }^{4}$ CINATTI. Obra poética, p. 41.

${ }^{5}$ CINATTI. Obra poética, p. 41.

${ }^{6}$ CINATTI. Obra poética, p. 42.
} 
usarmos um termo pessoano) de sujeito da escrita esteja completo: "Os Timorenses só terão razão/ quando me matarem". De resto, o poema explicita que a questão aqui é de ordem discursiva e que há representações de parte a parte que permanecem num conflito irresolúvel:

\section{Fugir é atrasar \\ o discurso limite travado pelas rodas da dúvida maníaca. ${ }^{7}$}

Perante o conflito, a única solução é fugir, ou seja, sair do seio da produção de discursos conflituais que reside no fulcro da relação colonial, ainda que essa fuga seja, em última instância, apenas um atraso na resolução da seguinte questão: pode o subalterno falar ${ }^{8}$ No final do poema ainda se mantém o que o poeta coloca de forma aguda, muito antes da formação da área dos Estudos Pós-coloniais, nos anos 70.

O mais curioso é que Ruy Cinatti faz tudo isto sem nunca abandonar uma postura ideológica colonial, o que cria uma situação muitíssimo ambivalente, pois toda a poesia sobre Timor, além da valorização da dimensão natural da ilha, é uma denúncia constante da exploração e da intervenção humana no ambiente, não hesitando em apontar o dedo aos governos coloniais dos quais fez parte. Cinatti faz, assim, uma espécie de auto-crítica do colonialismo português, ${ }^{9}$ sem contudo deixar de se inscrever nesse sistema e sem dar o salto para o anticolonialismo. Como deixa claro na advertência final do livro Paisagens timorenses com vultos (1974) onde, embora paradoxalmente dê vivas à autodeterminação de Timor e dos timorenses, considera serem absurdas e abusivas, palavras suas, a sua independência ou a sua adesão à Indonésia.

Com efeito, Cinatti encarna as contradições, em termos ideológicos, do ideário lusotropicalista que o império português reciclou em sua fase de declínio, entre 1951 e 1975, como tem sido discutido

\footnotetext{
${ }^{7}$ CINATTI. Obra poética, p. 42.

${ }^{8}$ Pergunta que dá título a um famoso ensaio de Gayatri Spivak, um clássico dos "Subaltern Studies" e dos Estudos Pós-Coloniais publicado em 1983.

${ }^{9} \mathrm{O}$ que sem dúvida lhe terá criado problemas na sua vida prática. Com efeito, depois de ter sido chefe de gabinete do governador desta colónia portuguesa entre 1946 e 1948, o poeta se incompatibiliza com a administração colonial nos anos 50. As visitas a Timor ficarão cada vez mais condicionadas, até à definitiva proibição em 1966.
} 
por estudiosos como Cláudia Castelo. ${ }^{10}$ Cinatti é um desses intelectuais portugueses do termo do império apostados em fazer uma realidade do discurso oficial que considerava o colonialismo português como sendo mais humano, por ser de matriz cristã, implicado que a violência e a agressão ínsita no ato colonial surgissem sob a imagem do paternalismo pelas culturas ditas menos desenvolvidas.

No entanto, e apesar de tudo isto, um poema como o que tratamos constitui uma desconstrução radical da lógica colonial. Nunca procurando corrigir o timorense, senão a partir dos seus desejos e realidades, o poema abre fraturas ou feridas incuráveis no pensamento colonial. Diferentemente da escrita etnográfica oitocentista, em que há um observador europeu e um "selvagem", cujos lugares nunca são discutidos, o que há em Cinatti é uma permanente negociação do lugar do sujeito e do objeto no seio da observação poética. Por esta razão, Cinatti não pode, quanto a mim, ser inscrito na linhagem do exotismo ou do orientalismo na literatura portuguesa. Ao contrário do discurso exótico, a poesia cinattiana seria um constante diálogo interno, não uma representação unilateral. Como afirmou Jorge de Sena:

[Timor] não é porém, nele, uma paisagem literária, ou um daqueles pequenos mundos a que os poetas se agarram para criar-se uma pequena mitologia própria; é mais: um objeto em que se concretiza a aproximação do poeta consigo mesmo e com a vida humana dos outros. ${ }^{11}$

Assim, mais do que o que a afirmação de Sena supõe, o mundo extra-europeu de Cinatti seria não apenas um mundo alheio aos discursos do exotismo, do orientalismo e do primitivismo, mas a sua ativa e meditada desconstrução a partir da representação tendencialmente questionadora da própria relação com o "outro".

\footnotetext{
${ }^{10}$ CASTELO. O modo português de estar no mundo: o luso-tropicalismo e a ideologia colonial portuguesa: 1933-1961.

${ }^{11}$ SENA. Prefácio a Paisagens timorenses com vultos, p. 485.
} 


\section{Antropologia e estética, poesia e ciência}

Como se acabou de ver, é central a inscrição antropológica na poesia cinattiana, o que permite lê-la como um lugar de negociação da alteridade. Porém, ressalto que isso é feito a partir da noção da poesia moderna enquanto espaço que implica a dimensão crítica, e não como mero campo passivo para plasmar questões culturais que lhe seriam exteriores ou estranhas. A questão antropológica é, assim, central para entender essa poesia enquanto objeto estético, não funcionando, na verdade, as duas dimensões de forma distinta.

Deste modo, a etnografia não será apenas, ao modo do simbolismo, uma metáfora para a escrita poética mas, talvez mais do que isso, a face de um projeto múltiplo: fazer do livro de poesia um "caderno de campo", móvel e aberto, passível de reescrita, e por isso, um livro essencialmente moderno. Daí o poeta se auto-intitular, em poesia inédita de 1981: "marujo em terra, silvicultor, etno-poeta". ${ }^{12}$ Tal como o trabalho de campo da antropologia moderna, trata-se de um processo sempre sensível à auto-correção. O seu objetivo não é apenas dar voz ao objeto, mas, mais do que isso, partilhar com ele a autoria da pesquisa.

Com efeito, enquanto trabalho de campo, a poesia de Cinatti pode ser esclarecida a partir do conceito de "registro". Estes livros de poesia sobre Timor constituem um registro do real que não se fecha na exatidão das imagens mas que, ao contrário, abrem essas imagens para o estremecimento emocional, tomando-as por base do comentário político, histórico, urbanístico, ecológico e científico que desenvolve nos poemas.

Vários dos poemas de um outro livro sobre Timor, com o título Paisagens timorenses com vultos (1974), desenvolvem uma aplicação muito literal desta capacidade de registro, noticiando ou listando objetos, espaços naturais, pessoas, cidades. A escrita cinattiana buscaria, com efeito, o entendimento entre poesia e observação antropológica, defendendo o que designa como o "conhecimento poético" enquanto uma das possíveis práticas científicas, no encalço de Goethe e de Novalis. Como afirma o autor, num comentário crítico à obra de Alberto Osório de Castro:

${ }^{12}$ O poema "Companheiros dos Mares", com a data de 5 de setembro de 1983, terá sido distribuído xerocado na rua, como era prática do poeta em seus últimos anos de vida. É transcrito em Jornal de Letras, Artes e Ideias, Lisboa, p. 5-7, 20 out. 1986. 
Não se pode ir mais longe na descrição, ao mesmo tempo poética e exata, científica e literária, provando-se, uma vez mais, que o conhecimento poético supera o conhecimento científico quando aquele afina pelo tom da verdade objetiva. ${ }^{13}$

Formulações como estas vão ecoar em toda a sua obra, propondo o fim da antinomia entre poesia e ciências, quer naturais, quer humanas. Há uma forma poética de registar o trabalho de observação que é, talvez, o aspecto mais relevante do diálogo de Cinatti com o conhecimento científico e que implica não apenas uma inspiração na praxis científica do trabalho de campo, mas um descentramento da noção de autoria.

Assim, um dos aspectos mais importantes da dimensão crítica e auto-reflexiva da poesia de Cinatti seria recuperar para si uma inscrição antropológica, um espaço para o outro, também ao nível da própria composição poética e estruturação do livro de poesia. Ora, a intersecção das ciências mobiliza esta propensão, através do cruzamento entre poesia e botânica, geografia, história e antropologia, que são formas (muitas delas já descentradas em termos de autoria ou mesmo coletivas) de, em conjunto, falar com o outro. Tal processo perfila a combinação harmônica do discurso científico e pragmático e do discurso poético que a sua escrita visa, sobretudo nas obras sobre Timor.

Enquanto forma aberta, o livro de poesia Paisagens timorenses com Vultos realiza-o incorporando processos do discurso científico, tais como notas e anexos aos textos. Trata-se de uma prática que não é estranha à literatura colonial portuguesa, como Alberto Osório de Castro bem demonstra sendo, de outra parte, um conhecido gesto da poesia moderna. As notas de The waste land (1922) de T. S. Eliot, por exemplo, encarnam o criticismo poético a partir desses elementos paratextuais, bem como as de Jorge de Sena, autor que de modo obsessivo circunstancializa os seus poemas com referências às datas e lugares de composição. Já as notas de Paisagens timorenses com vultos (1974) de Ruy Cinatti, claramente inspiradas no pendor digressivo de um livro de Alberto Osório de Castro de nome Flores de coral (1909), que constituía uma referência para Cinatti, herdam, no contexto da poesia moderna, a herança do trabalho de registo e de observação que é, talvez, o aspecto mais relevante do trabalho de Osório de Castro.

${ }^{13}$ CINATTI. Obra poética, p. 561. 
Assim, a forma como nos poemas timorenses de Cinatti, a poesia é chamada a realizar este encontro implica que esta devenha enquanto corografia, isto é, registro de campo de um terreno concreto. E note-se, a este respeito, que uma das secções do livro em questão se intitula Para uma corografia emotiva de Timor (1946-1972). Assim, um livro como este, dedicado ao território de Timor, realiza na literatura portuguesa um velho projeto modernista, tal como programado por Apollinaire em L'Esprit nouveau et les Poètes (1918), e que vai mais longe do que o uso da ciência e da pesquisa como metáforas da poesia, conforme proposto pelo simbolismo. Com efeito, o que o poeta francês afirma em 1918 é já bem diferente:

Quand un poète moderne note à plusieurs voix le vrombissement d'un avion, il faut y voir avant tout le désir du poète d'habituer son esprit à la réalite. Sa passion de la vérité le pousse à prendre des notes presque scientifiques qui, s'il veut les présenter comme poèmes, ont le tort d'être pour ainsi dire des trompe-oreilles aux quels la réalité sera toujours supérieure. (...) Mais leurs recherches seront utiles; elles constitueront les bases d'un nouveau réalisme qui ne sera peut-être pas inférieur à celui si poétique et si savant de la Grèce antique. ${ }^{14}$

Se descontarmos o tópico vanguardista da excitação pela entrada em cena da tecnologia na literatura, aumentando as capacidades perceptivas e expressionais do poeta, ficamos com a noção de que a poesia permite reunir de forma não-contraditória, ainda que possivelmente violenta ou chocante, discursos que até então estiveram fora dela.

Em termos contrários a estes, a formulação da relação entre poesia e ciência como oposição irreconciliável teve um momento importante no século XIX português, com Antero de Quental, que no opúsculo $A$ Poesia na atualidade (1881) glosou o tópico oitocentista da morte da arte às mãos da ciência. Este tema vai voltar a ser endereçado em 1910 - em sentido distinto do de Antero - por Camilo Pessanha, numa importante resenha ao referido livro Flores de coral de Alberto Osório de Castro, não por acaso um livro de poemas também sobre Timor. ${ }^{15}$

\footnotetext{
${ }^{14}$ APOLLINAIRE. L'Esprit nouveau et les poètes.

${ }^{15}$ Cf. RUBIM. Camilo Pessanha e a questão da poesia.
} 
O contraponto da atitude de tornar científica a poesia não é, contudo, menos importante: haveria que desenvolver uma ciência que fosse, antes de mais, uma verdadeira atitude poética perante o mundo, no sentido de uma compreensão global acompanhada de uma transformação criativa, ao modo do Romantismo Alemão. Citando Novalis:

A forma perfeita e acabada das ciências tem de ser poética. Cada proposição tem de ter um caráter autônomo - ser um indivíduo inteligível por si, invólucro de uma inspiração chistosa. ${ }^{16}$

Desta maneira, não é só a poesia que fará uso de processos científicos, mas também a própria ciência terá um Devir poético. Ou seja, o criticismo poético, acompanhado de seus traços já bem conhecidos: a impessoalidade, o questionamento do sujeito, é acompanhado de uma transformação do mundo, deste modo resolvendo o contraste entre a tão propalada impessoalidade da poesia moderna e um mundo que se veio tornando ausente de humanidade e desprovido de fascínio.

\section{Referências}

APOLLINAIRE, Guillaume. L'Esprit nouveau et les poètes. Mercure de France, n. 130, p. 385-396, 1 dez. 1918.

CASTELO, Cláudia. O modo português de estar no mundo: o lusotropicalismo e a ideologia colonial portuguesa: 1933-1961. Porto: Edições Afrontamento, 1999.

CINATTI, Ruy. Uma sequência timorense. Braga: Pax, 1970.

CINATTI, Ruy. Obra poética. Org. e pref. Fernando Pinto do Amaral. Lisboa: Imprensa Nacional-Casa da Moeda, 1992.

NOVALIS. Pólen. Trad. Rubens Rodrigues Torres Filho. São Paulo: Iluminuras, 1988.

RUBIM, Gustavo. Camilo Pessanha e a questão da poesia. Lisboa: Caminho, 1995.

${ }^{16}$ NOVALIS. Pólen, frag. 17. 